\title{
The properties of concrete mixes, pumped over long distances
}

\author{
Viktor Sopov ${ }^{1, *}$, and Viktor Dolgiy ${ }^{1}$ \\ ${ }^{1}$ Kharkiv National University of Civil Engineering and Architecture, Department of Physical and \\ Chemical Mechanics and Technologies of Building Materials and Products, Sumska st. 40, 61002 \\ Kharkiv, Ukraine
}

\begin{abstract}
The influence of technological factors, chemical and mineral admixtures on pumping and thixotropic properties of concrete mixtures was studied. The causes of the loss of pressure when pumping concrete mixtures through channels of a complex section are established. Existing methods for calculating pressure loss during pumping of concrete mixtures are considered. Some results of pumping tests of modern concrete mixtures are given. It is shown that the use of powdered concrete with high mobility for pumping over long distances during the filling of long-span metal or bridge structures, concreting in tunnels where injection pressure is limited, can be the only solution in the implementation of these tasks.
\end{abstract}

\section{Relevance of the problem}

In the last decade, great progress has been made in pumping concrete mixes with pump equipment [1-3]. Practical recommendations for concrete pumps have been developed, basic principles of pumping have been defined, etc. But all these knowledge and rules focus on vibrating heavy concrete (CVC). Pumping of other modern types of concrete mixtures has not been sufficiently studied today. Recommendations for pumping vibrating heavy concrete will not meet the necessary conditions when pumping self-compacting concrete mixtures (SCC), mortars, fine grained concrete mixtures and powdered concrete (RPC).

In practice, the study of pumping concrete mixtures is associated with the determination of pressure losses in the system using certain pumping equipment. The causes of pressure loss can be:

- Technological (configuration, material, length and diameter of the concrete, the pressure of the concrete pump, the type of the concrete pump, the speed of the concrete mix in the concrete, the temperature of the mixture and the ambient air);

- Rheological (shear stress, yield strength, viscosity, structural strength of the mixture, thixotropy);

- Tribological (friction and lubricating layer).

Technological reasons for the loss of pressure in the concrete guide are associated with pumping equipment. In a number of cases, the calculation of the required pressure reduces to the calculation of only technological parameters without taking into account the

Corresponding author: vsopov1959@hotmail.com 
rheological properties of the concrete mixture [4]. For vibrational concretes this may be the case.However, the properties of modern concrete mixtures and concretes can be very different from those of CVC. Therefore, for more accurate prediction of pressure losses when pumping modern concrete, it is necessary to take into account the rheological and tribological characteristics of it.

\section{Theoretical basis}

Modern studies of pumping concrete are devoted to rheological and tribological (tribology the science of the processes of friction and lubrication) characteristics of the flow of concrete mixture [5]. In this case, the main role is assigned to the lubricating layer (Fig. 1).

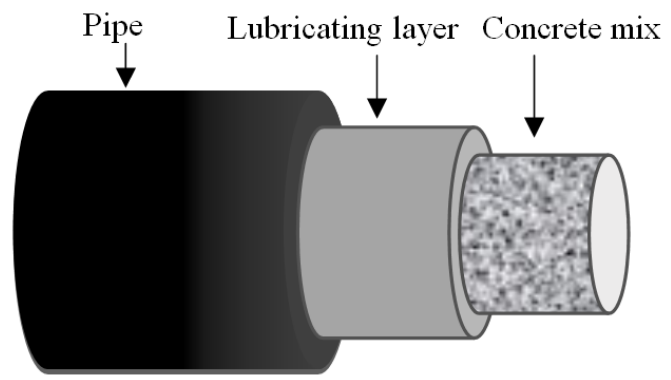

Fig.1. Schematic representation of a concrete mix in a pipe.

The most accepted approach in the quantitative evaluation of the rheological properties of a concrete mixture is the measurement of the shear stress as a function of the shear rate, since the readings of the sediment or the spreading of the cone do not give a complete picture of the processes occurring in the mixture during pumping. The rheological model of concrete mixtures obeys the Bingham law, where the shear stress depends on the shear rate [6], i.e. non-Newtonian fluid (Fig. 2):

$$
\tau=\tau_{0}+\frac{\mu}{\gamma}
$$

where $\gamma$ is the velocity gradient, $\mu$ and $\tau_{0}$ are the plastic viscosity and yield stress, respectively.

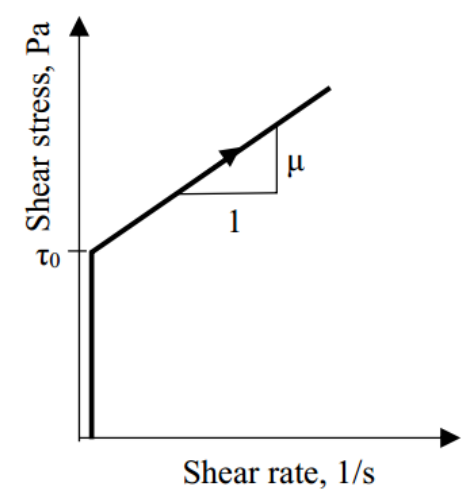

Fig. 2. Dependence of shear stress on shear rate for cement systems.

The non-Newtonian behavior of concrete mixtures is determined by the strength of the spatial structure of the disperse system, which is directly related to the nature of its 
behavior during flow, as well as its speed of destruction and recovery. The flow of cement systems occurs together with the destruction of the spatial structure and, the more the flow velocity, the more the system, the viscosity of which decreases, decreases. At the same time, as a result of the chemical reaction, the limit of temperature and plastic viscosity vary with time. The presence of the structure gives the system properties of ductility, fluidity, and viscosity.

Thixotropyis defined as a decrease in viscosity when applying shear, and then gradual recovery when shearing stresses are removed. An interesting feature is the cement system in determining the viscosity with increasing the shear rate and then reducing it, forming, socalled, hysteresis loops [7]. Those. The yield strength decreases as the total amount of shear energy increases. And important is the dependence of the yield point on the history of shear stresses. The shape of the loop varies depending on the cycle time, when the shear stress is increased due to hydration during a long cycle (Fig. 3) [7].

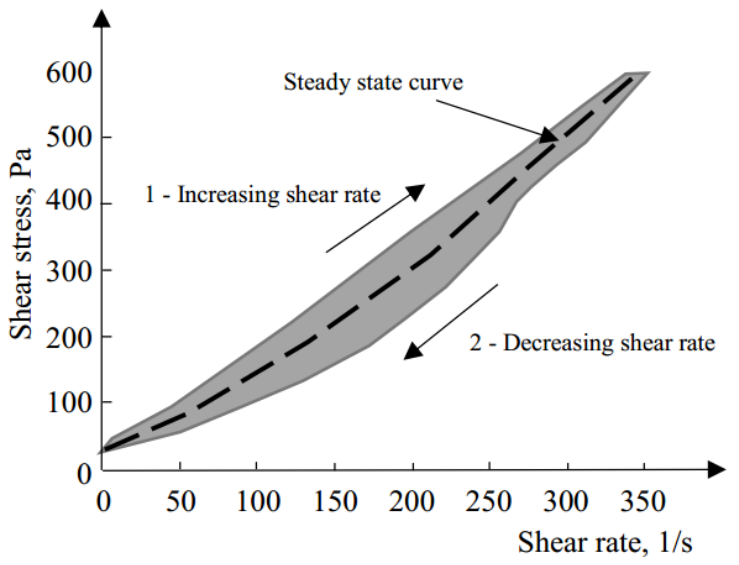

Fig. 3. Example of thixotropic loop obtained with a cement paste [7].

The components of the concrete mix differently affect its rheological properties. The influence of organic superplasticizers is caused by a decrease in the yield strength of the concrete mix without a significant effect on its viscosity. Similarly, an increase in the air content of the mixture affects the decrease in its plastic viscosity (Fig. 4). The increase in mixing water leads to a mutual decrease in rheological parameters. An interesting feature is the additive of microsilica - with increasing its content, viscosity decreases, and at a flow rate of more than $25 \%$ of cement mass, the yield strength of the cement system rises sharply. The addition of fly ash largely affects the yield strength and has a slight effect on the viscosity change.

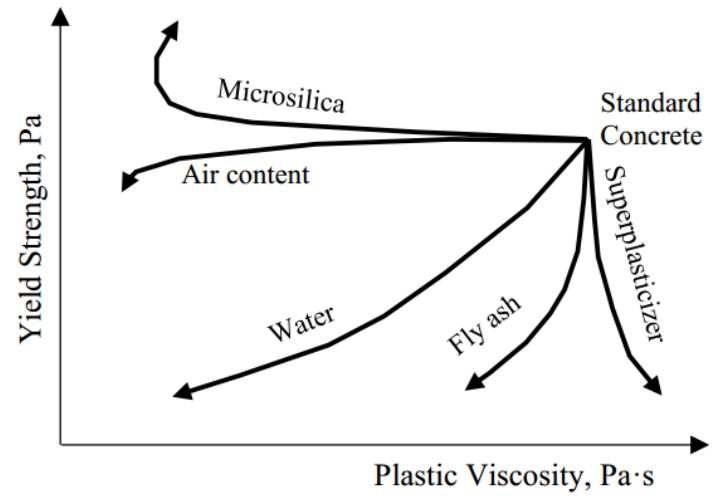

Fig. 4. Effect of components of a concrete mixture on its rheological characteristics. 
The development of new-generation concrete technology is associated with a reduction in aggregate fractions [8]. So, for example, for ultrahigh-strength concrete (UHPC) (over $100 \mathrm{MPa}$ ), the particle size of the aggregate is commensurate with the cement particles. Such concrete is devoid of shortcomings of the contact zone with inert aggregates, where all components enter into chemical reactions, forming a more solid structure.

Replacement of a large aggregate with finely divided mineral additives gives a great advantage in pumping such mixtures due to the practical exclusion of sedimentation of large grains and obtaining a more homogeneous structure of the pumped material. Based on the properties of reactive powdered concrete, their use makes it possible to produce concrete mixtures with mobility that goes far beyond self-compacting concrete (EN 206-9) with high final characteristics, corresponding to new-generation concrete. This opens up a wide range of possibilities associated with pumping concrete over long distances, filling in elements of complex configuration, obtaining high-quality surfaces, etc.

\section{Experimental part}

The experiment consisted in determining the pressure loss in the pipe section $99 \mathrm{~m}$ when the concrete pump was pumped by a highly mobile concrete mix by measuring the internal pressure in the concrete guide at the beginning and middle of the concrete pipe (Fig. 5). Auto-concrete pump hydraulic with the length of the stroke of the piston $1500 \mathrm{~mm}$ and the developed pressure on the concrete mixture to $4 \mathrm{MPa}$. The choice of the composition of concrete was carried out from the conditions of the greatest distance of pumping of the concrete mixture through a concrete guide of rectangular cross-section $60 \times 80 \mathrm{~mm}$. The maximum aggregate size was $0.2 \mathrm{~mm}$.

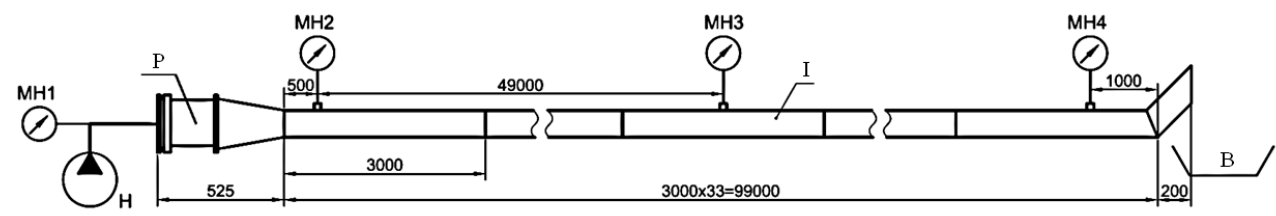

Fig. 5. General scheme of concrete pipe: I - Concrete pipe of rectangular cross-section $60 \times 80 \mathrm{~mm} ; \mathrm{H}$ - concrete pump; $\mathrm{B}$ - a container for draining a concrete mixture; $\mathrm{P}$ - adapter to the concrete pump; MH1-MH4 - manometers with membrane media separators.

The mobility of the concrete mixture was determined by the spreading of the Abrams cone and the Suttardviscosimeter, and its rheological characteristics by means of rotary viscosimeter of a Fungilab Expert L. The diffusion of the Abrams cone was $104 \mathrm{~cm}$, the expansion of the Suttard viscometer cylinder was $20 \mathrm{~cm}$ and the dynamic viscosity on the rotational viscometer was $1274-5317 \mathrm{cP}$, depending on the shear rate (Fig. 6 and Fig. 7).

The speed of the concrete mix was $0.9 \mathrm{~m} / \mathrm{s}$ at the minimum speed of the concrete pump. 


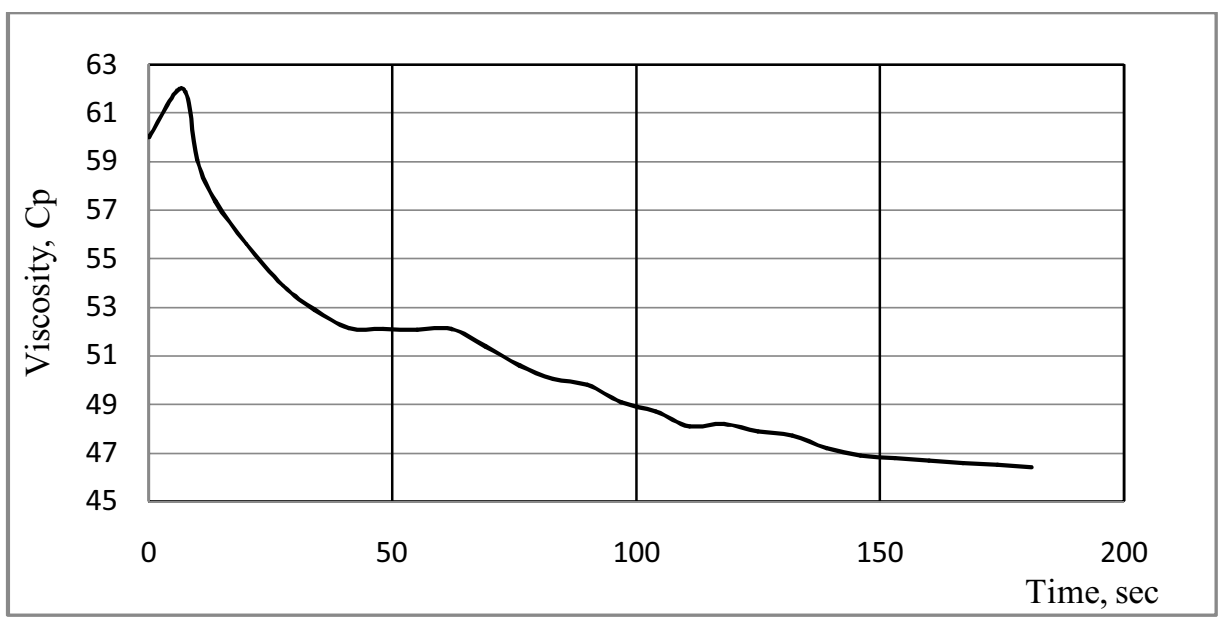

Fig. 6.The viscosity of the concrete mix at a spindle rotation speed of the viscometer $20 \mathrm{rpm}$.

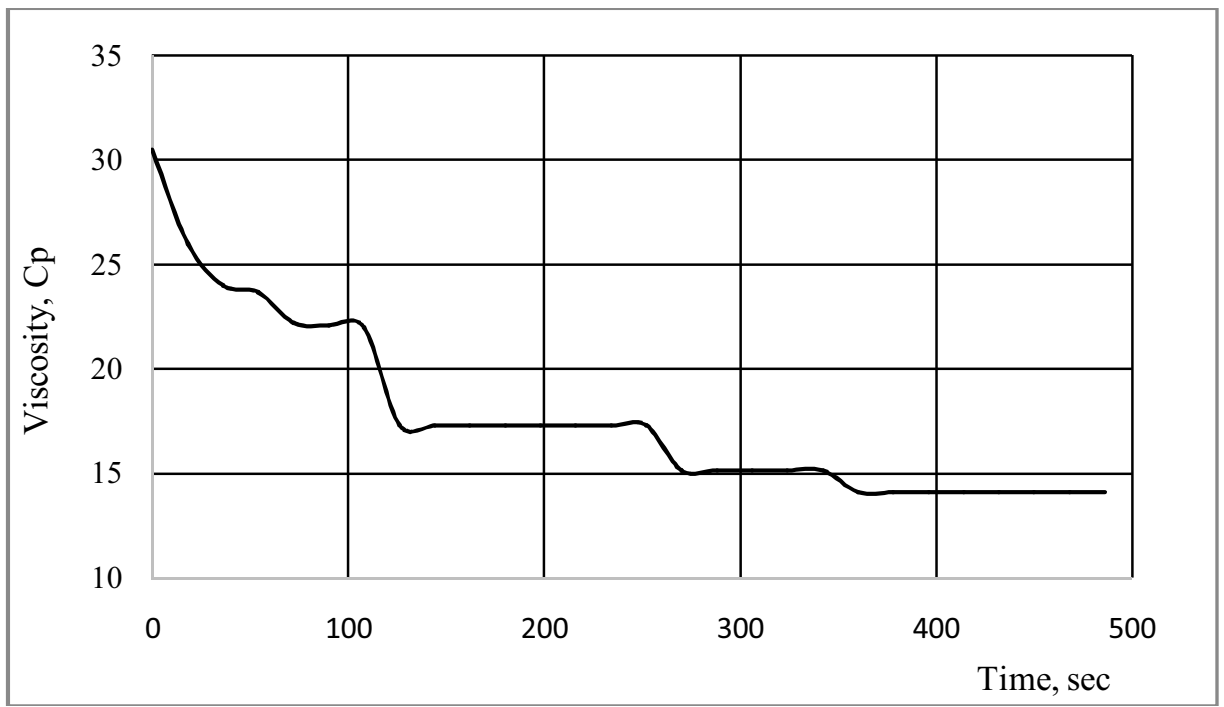

Fig. 7. The viscosity of a concrete mix at a speed of rotation of a spindle of a viscosimeter $40-$ $100 \mathrm{rpm}$.

The readings of the manometer $\mathrm{MH} 2$ are unstable in the range of $0.0-0.4 \mathrm{MPa}$, the MH3 readings are more stable and are in the range of 0.0-0.1 MPa. Starting from 100 seconds the steady flow is observed according to the readings of the MH3 manometer, which coincides with the time of the mixture exit from the concrete guide. The presence of the $\mathrm{MH} 2$ manometer in close proximity to the concrete pump, which generates alternate translational movements of 2 pistons with a length of $1500 \mathrm{~mm}$, shows the actual instability of pressure in the pipe at the very beginning (Fig. 8). 


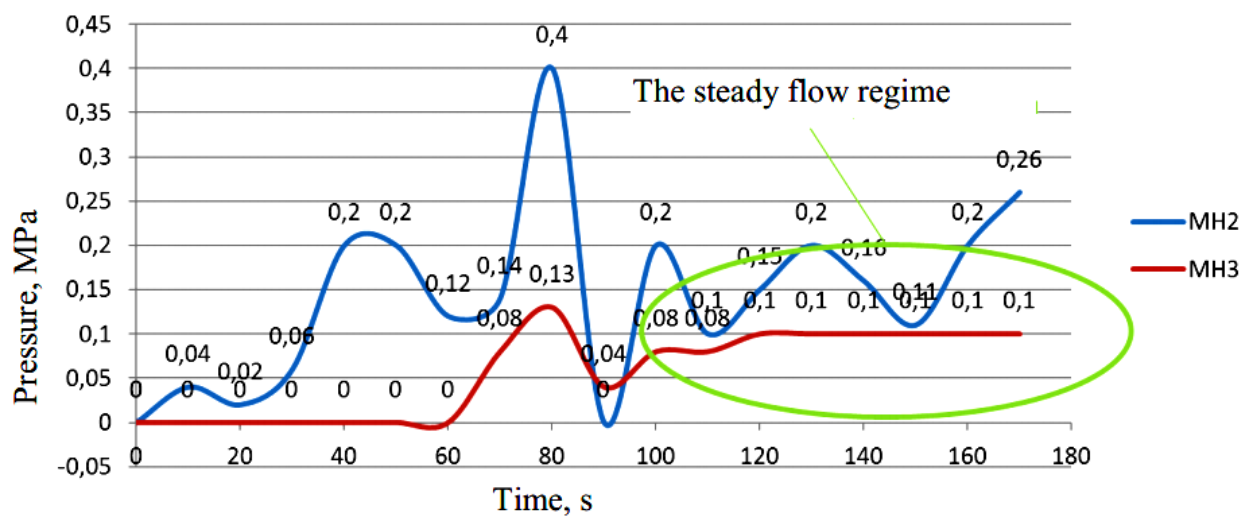

Fig. 8. Changing the pressure in the pipe in time when pouring the concrete mixture.

\section{Discussion of results}

In the process of injection at some point in time, the concrete pump begins to apply a constant force (Fig. 9). All the liquid in the pipe immediately come into motion can not. Just before the piston, there will be a compression region, which begins to propagate through the pipe, moving more and more distant areas of liquid inside the pipe.

The velocity of propagation of the compression region coincides with the speed of sound in this liquid. Finally, after a short period of time, a pressure distribution is established in the tube, which ensures the constancy of velocity along the tube [9]. Those. The curves $\mathrm{MH} 2$ and $\mathrm{MH} 3$ of the readings of the pressure gauges on the graph (Fig. 8) after $100 \mathrm{~s}$ show the already established flow regime, which determines this phenomenon.

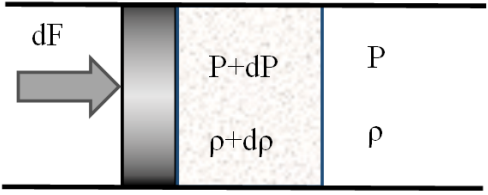

Fig. 9. Transfer of pressure from the piston.

Anyway, the pumping of concrete mixtures over long distances is associated with the use of powerful pumping equipment. However, if technological pressure losses depend on the choice of pumping equipment, then rheological and tribological depend on the composition of the mixture and, taking into account the specific features of the influence of individual components of the concrete mixture on its rheological properties, it is possible to significantly influence the pumping distance by choosing the optimal composition. Increase pumping capacity of concrete can be due to the modification of their compositions and the obtaining of viscosity and spreadability, which is beyond the scope of the classification by standards. Reducing the viscosity of mixtures should be accompanied by the preservation of uniformity.

\section{Conclusions}

Exclusion of a large aggregate will solve a number of problems associated with segregation of the mixture under pressure, and the introduction of organic and finely dispersed mineral additives will ensure uniformity of the mixture during pumping and high final 
characteristics of the concrete. The use of powdered concrete with high mobility for pumping over long distances when filling long-span metal or bridge structures, concreting in tunnels where injection pressure is limited, can be the only solution in the implementation of these tasks.

\section{References}

1. Concrete Society. Pumping concrete, Good Concrete Guide 2, Surrey,14 (2005)

2. P.J.M. Bartos, M. Sonebi, A.K. Tamimi, Workability and rheology of fresh concrete: compendium of tests, Report of Rilem TC 145-WSM, Workability of special concrete mixtures, 127 (2002)

3. D. Kaplan, Pompage des bétons, Ph.D.-thesis, Laboratoire Central des Pontset Chaussées, (In French), 228(2001)

4. N. Roussel, RILEM Mater. Struct. 39 (1), 75-83 (2006)

5. G.Tattersall, Workability and Quality Control of Concrete Tattersall, G London, E \& FNSPON, 262 (1991)

6. O.Wallevik, Proc 3rd IntSymp on Self-Compacting Concrete, Reykjavik, 23-31 (2003)

7. N. Roussel, Cem. Concr. Res., 36, 1797-1806 (2006)

8. P. F. G. Banfill, Rheology Reviews, 61-130 (2006)

9. Jae Hong Kima, SeungHee Kwon, Shiho Kawashima, Hong Jae Yim, Cem. Concr. Res., 77, 60-67 (2017) 